\title{
A review of the role of social cognition in major depressive disorder
}

\section{Michael James Weightman, Tracy Michele Air and Bernhard Theodor Baune*}

Discipline of Psychiatry, School of Medicine, The University of Adelaide, Adelaide, SA, Australia

Edited by:

Michael Noll-Hussong, University of Ulm, Germany

\section{Reviewed by:}

Peter Kirsch, Zentralinstitut für

Seelische Gesundheit, Germany

Renerio Fraguas, University of São

Paulo, Brazil

Farooq Naeem, Queens University,

Canada

*Correspondence:

Bernhard Theodor Baune, Discipline of Psychiatry, School of Medicine,

Level 4 Eleanor Harrald Building,

University of Adelaide, SA 5005,

Australia

e-mail: bernhard.baune@adelaide. edu.au
Background: Social cognition - the ability to identify, perceive, and interpret socially relevant information - is an important skill that plays a significant role in successful interpersonal functioning. Social cognitive performance is recognized to be impaired in several psychiatric conditions, but the relationship with major depressive disorder is less well understood. The aim of this review is to characterize the current understanding of: (i) the different domains of social cognition and a possible relationship with major depressive disorder, (ii) the clinical presentation of social cognition in acute and remitted depressive states, and (iii) the effect of severity of depression on social cognitive performance.

Methods: Electronic databases were searched to identify clinical studies investigating social cognition in a major depressive disorder population, yielding 31 studies for this review.

Results: Patients with major depressive disorder appear to interpret social cognitive stimuli differently to healthy controls: depressed individuals may interpret emotion through a mood-congruent bias and have difficulty with cognitive theory of mind tasks requiring interpretation of complex mental states. Social cognitive performance appears to be inversely associated with severity of depression, whilst the bias toward negative emotions persists even in remission. Some deficits may normalize following effective pharmacotherapy.

Conclusions: The difficulties with social interaction observed in major depressive disorder may, at least in part, be due to an altered ability to correctly interpret emotional stimuli and mental states. These features seem to persist even in remission, although some may respond to intervention. Further research is required in this area to better understand the functional impact of these findings and the way in which targeted therapy could aid depressed individuals with social interactions.

Keywords: social cognition, major depressive disorder, depression, facial affect, theory of mind

\section{BACKGROUND}

Correctly interpreting social information is a crucial part of successful interpersonal interaction. This requires synthesis of a broad range of verbal and non-verbal cues, including facial expressions, prosody in speech, body language, and the mental states of others (theory of mind). Together, these skills are referred to as social cognition and are an important component of cognitive functioning. Social cognition encompasses the identification, perception, and interpretation of socially important information (1), whilst the domain of theory of mind specifically refers to the ability to infer information regarding the thoughts, intentions, and feelings of others (2). This is further conceptualized into two distinct systems - cognitive theory of mind relates to interpretation of beliefs and intentions, whilst affective theory of mind consists of inferences regarding the emotional states of others (3).

Social cognitive impairment is widely recognized to be a key feature of several psychiatric diseases, such as schizophrenia (1) and autism (4). The impact of depression on social cognitive functioning is less well understood, although there is some evidence to suggest that a similar, albeit less severe, impairment of social cognition may be seen in patients with major depressive disorder. Whilst major depressive disorder is primarily characterized by emotional symptoms such as low mood and anhedonia (5), individuals with depression have also been found to display profound and pervasive impairments in interpersonal functioning (6). Nevertheless, depressed patients appear to be less severely impaired in social cognition than patients with schizophrenia or autism (7-9).

The majority of data from previous reviews investigating the relationship between depression and social cognition relate primarily to the emotional domain, particularly through facial expressions or affective theory of mind. One meta-analysis of eight studies found major depressive disorder to be significantly associated with impaired recognition of emotional facial expressions with a moderate overall effect size (10). A larger review indicated a reasonably consistent pattern of a negative interpretive bias of facial affect (11). It appears that depressed patients may not exhibit diminished recognition accuracy when interpreting facial expressions, but rather demonstrate an increased sensitivity toward sad 
expressions in comparison to happy ones. Other reviews have indicated that such abnormalities appear to respond to anti-depressant therapy and may actually be detectable prior to improvements in $\operatorname{mood}(12,13)$.

To our knowledge, there is a lack of similar comprehensive reviews of behavioral studies in the domains of prosody, body language, and theory of mind to determine if these findings are consistent across all components of social cognition in major depressive disorder. Evidence from individual studies indicates that patients with major depressive disorder may also struggle with verbal cues, with two studies reporting a negative bias when depressed patients interpret prosodic stimuli $(14,15)$. Several authors who have tested theory of mind performance in depressed cohorts have found them to be impaired, albeit less severely than psychotic or autistic participants $(7,8)$. It is therefore reasonable to anticipate that the impairments in social cognition in major depressive disorder may translate across the different domains.

In addition to the available behavioral data, there is also a significant body of literature that exists on functional neuroimaging in patients with depression undergoing social cognitive testing. Much of this literature indicates a neural basis for the observed phenomenology, primarily centering around dysregulation of both the amygdala and ventromedial frontal cortex (16-19). In light of such functional changes, detailed examination is required to determine the extent to which altered processing of social stimuli may impact the quality of life or interpersonal success of an individual with major depressive disorder.

Better understanding of the nature of social cognition in major depressive disorder is important, as it will help to further characterize the phenotype of the disease and may offer explanation for the poor social functioning observed in depression. It is also important to consider the potential therapeutic implications, as previous reviews have suggested that impairments in social cognition may be reversible $(12,13)$. Improvement in social cognitive functioning may become a targeted component of the treatment for depression or a useful method of monitoring improvement.

The present review of the existing literature on social cognition and major depressive disorder aims to increase the understanding of: (i) the impact of depressed mood across different domains of social cognition including facial affect, prosody, body language, and theory of mind, (ii) the clinical presentation of social cognition in acute and remitted depressive states, and (iii) the effect of severity of depression on social cognitive performance.

\section{METHODS}

\section{SEARCH STRATEGY}

An electronic search strategy was employed to identify published studies investigating the behavioral relationship between social cognition and depression. Pertinent original research articles were identified and retrieved via the Medline, Embase, and PsycINFO databases, as well as the reference lists of included articles. The search was limited to only the most recent English literature, taking into account the 10-year period from June 2003 to June 2013. The subject headings used across the different databases were "social cognition," "social perception," "depression," "major depression," "mood disorders," "depressive disorder," and "affective disorders." This was combined with the key word search terms of "social cognition," "social perception," "social interaction," "depression," "mood disorder," "affective disorder," "melancholia," and "dysthymia." Truncated search terms were included where possible to maximize results, while inclusion of broad key words such as "mood disorder," "melancholia," or "dysthymia" was intended to enhance the sensitivity of the search.

\section{STUDY SELECTION}

The titles and abstracts of the results generated from the three databases were screened to exclude irrelevant articles. The full articles of the remaining studies were downloaded and the methods inspected in detail to determine eligibility (Figure 1). The identified studies were included in the analysis if they met the following criteria: firstly, the diagnosis of an acute or remitted major depressive disorder was formally made according to a standardized interview; secondly, the patient population needed to be an adult study group, defined as participants aged 18 and above; thirdly, each study was required to report behavioral data relating to a social cognitive task in one or more of the following domains only - facial affect recognition, theory of mind, prosody, or body language interpretation.

Studies were excluded if the patient group was co-morbid with a separate psychiatric disorder, such as schizophrenia, dementia, a learning disorder, eating disorder, or pervasive developmental disorder. Studies were also excluded if the patient group demonstrated bipolar features. Functional MRI studies with no reported behavioral results were excluded. Once selected, the article's reference list was then scoured for further relevant articles missed in the initial database searches.

\section{RESULTS}

Over the past decade, much has been published to further characterize the relationship between social cognition and major depressive disorder. Following a thorough search of the literature, a total of 31 articles were included in this review (Figure 1).

Social cognition is a broad term encompassing a diverse array of skills. The two most studied social cognitive domains are facial affect recognition and theory of mind, with the majority of included studies in this review investigating ability in these two areas. Some authors have applied a bimodal approach to assessing social cognition, using both a perceptual assessment of observable social information for facial affect with a more conceptual approach involving higher order functions for theory of mind (2, $7,8,20,21)$. Others have included empathy $(2,22)$ among the domains of social cognition. No studies were uncovered using the above methodology that specifically investigated prosody of voice or body language, although body language was indirectly assessed in the tasks used by some authors $(2,22)$. This suggests a need for further research into the impact on other social cognitive domains in major depressive disorder.

\section{MAJOR DEPRESSIVE DISORDER AND FUNCTION ON SPECIFIC DOMAINS OF SOCIAL COGNITION}

The literature remains equivocal regarding overall differences in social cognitive performance between depressed and healthy cohorts. While there is some evidence to suggest that subjects with major depressive disorder may demonstrate poorer overall social cognitive performance compared to healthy controls 


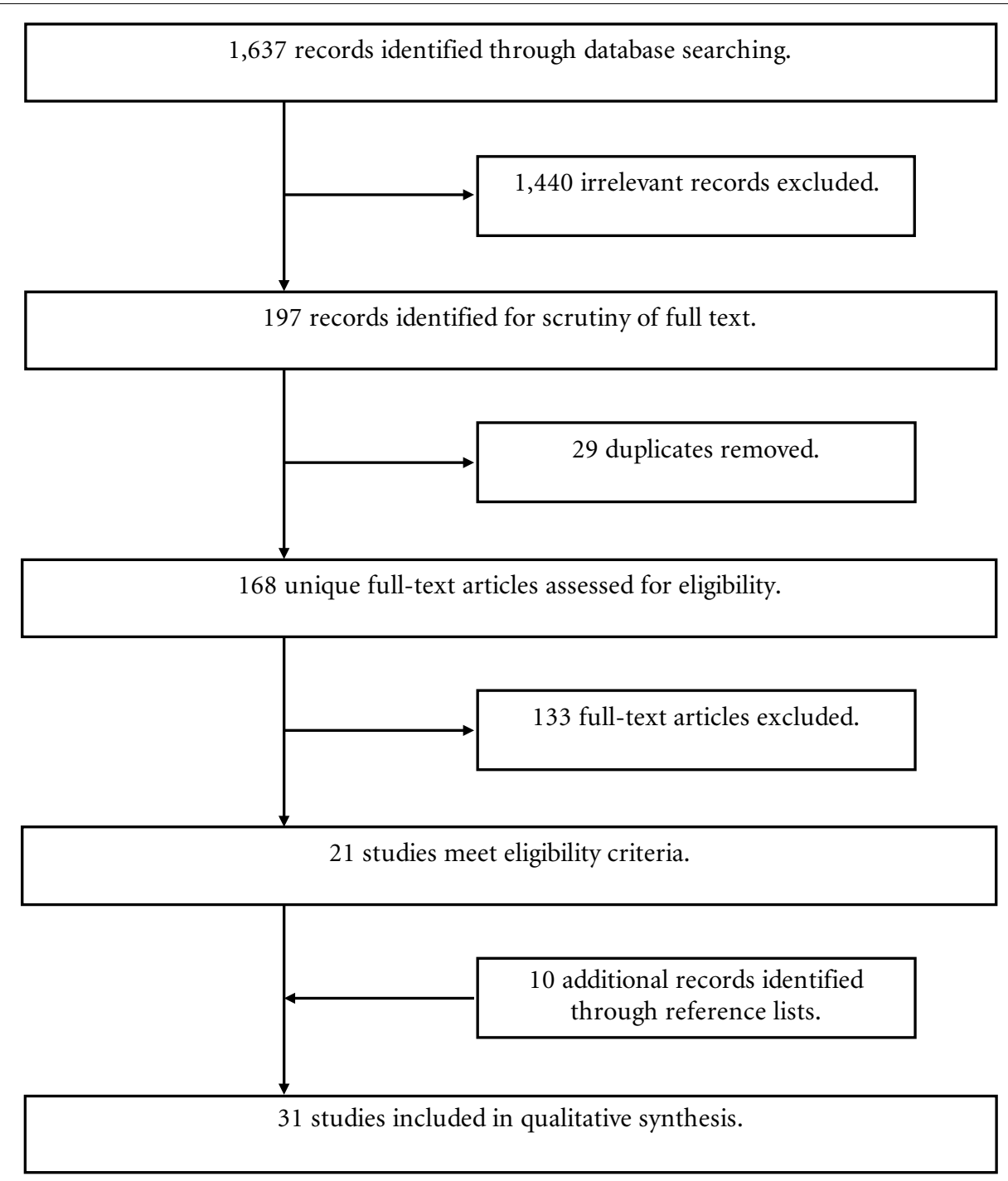

FIGURE 1 | Flowchart of article inclusion procedure during review of the literature. From 1,637 individual records initially identified through the literature search of the Medline, PsychINFO, and Embase databases, 31 articles were included in the final analysis.

(Table 1A), numerous other authors found no group difference on a gross measure of social cognition (Table 1B). This is further discussed below according to the domains of facial affect recognition, affective theory of mind, and cognitive theory of mind.

\section{Facial affect recognition}

The way in which depressed patients respond to emotional facial expressions can be broadly categorized according to valence of the emotion.

For neutral expressions, depressed patients appear to assign more negative interpretations than healthy controls (23, 30, $35)$, although this was not a consistent result. In some studies, depressed individuals were found to be significantly more likely to interpret a neutral stimulus as being sad $(23,35,36,42)$. In two small case-control studies involving 66 and 36 participants, respectively, Gollan et al. (35) and Leppänen et al. (30) found depressed participants identified more neutral expressions as sad than their non-depressed counterparts.

A similar bias is evident with respect to negatively valenced expressions (31), with some authors observing particular deficits for the expressions of sadness $(36,42)$ and fear $(43)$. In one large case-controlled study of 230 participants, Anderson et al. (23) noted a significant bias toward the identification of negative expressions, namely anger and sadness, by those with a current or past history of depression in comparison to control participants. A case study by Csukly et al. (24) found a significant reduction in the accuracy of both sad and neutral facial recognition by the depressed patient group.

Studies examining the interpretation of positively valenced expressions - such as happiness - in a depressed population show an even greater discrepancy between results. There is some evidence to suggest that patients with major depressive disorder are 
Table 1 | Case-control studies investigating differences in social cognitive performance between patients with major depressive disorder and controls

\begin{tabular}{lllll}
\hline References Aim & Method & $N$ [MA \pm SD; M:F $]$ & $\begin{array}{l}\text { Social cognition Mood } \\
\text { task }\end{array}$ & $\begin{array}{l}\text { Results } \\
\text { diagnosis }\end{array}$
\end{tabular}

\section{(A) STUDIES INDICATING SIGNIFICANT DIFFERENCES BETWEEN ACUTELY DEPRESSED INDIVIDUALS AND HEALTHY CONTROLS} To compare accuracy, discrimination, and bias in face recognition in current and remitted depression

Cao et al. (21) To investigate social cognitive performance in esophageal cancer patients with depression

Csukly To determine if depressed patients

et al. (24) and if this is due to emotional intensity and arousal

Csukly

et al. (25)

To identify associations between depressive severity, maladaptive schemas, and facial affect recognition

Donges et al. (26) To examine emotional awareness in depressed inpatients following a psychotherapy program

Harkness

To determine if maternal history of

et al. (27) depression impacts affective ToM performance

Langenecker To evaluate emotion perception deficits et al. (28) in depressed women

Outpatient sample

Lee et al. (29) To examine depressed patients' abilities to identify mental states from affective eye expressions

Leppänen To determine if depression biases the recognition of emotionally neutral faces

\section{Case-control}

$\mathrm{MDE}=30, \mathrm{rMDD}=99, \mathrm{HC}=101$

FERT

$[33.1 \pm 10.5 ; 71 \mathrm{M}: 159 \mathrm{~F}]$

Case-control

Esophageal cancer $\quad H C=62 n=127[33.1 \pm 10.5$;

$\mathrm{pMDD}=32, \mathrm{npMDD}=33$

RMET-R, FPT

DSM-IV

patient sample $\quad 71 \mathrm{M}: 159 \mathrm{~F}$

Case-control

$\mathrm{MDD}=23, \mathrm{HC}=23[48.4 \pm 12.5 ; \quad \mathrm{VHI}$

$18 \mathrm{M}: 28 \mathrm{Fl}$

Case-control

$M D D=107, H C=23[41.1 \pm 11.3 ; \quad V H I$

Inpatient sample 16M:90F

Prospective

longitudinal

$\mathrm{MDD}=22, \mathrm{HC}=22[32.1 \pm 8.6 ; \quad$ LEAS

case-control

Inpatient sample

Case-contro

$\mathrm{MDD}=61, \mathrm{HC}=30[45.3 \pm 14.5 . \quad$ RMET-R

Outpatient sample $\quad$ OM:91F]

$M D D=21, H C=20[30.9 \pm 9.2 ; \quad$ FEPT OM:41F]

Case-control

$\mathrm{MDD}=67, \mathrm{HC}=34[42.7 \pm 14.1 ; \quad$ RMET-R

Outpatient sample $\quad 0 \mathrm{M}: 82 \mathrm{~F}$

Case-contro

Inpatient sample
$\mathrm{MDD}=18, \mathrm{HC}=18[44.9 \pm 9.9 ; \quad$ PFA

$14 \mathrm{M}: 22 \mathrm{~F}$

Significant difference between MDE, rMDD and $\mathrm{HC}$ groups on facial affect recognition accuracy $\left(F_{2,225}=5.340, P=0.005\right)$

BDI-II

Compared to $\mathrm{HC}$, both MDD groups were impaired on affective ToM $(t=7.39, P<0.01)$ and faux pas task $(t=13.75, P<0.01)$

DSM-IV, $\quad$ MDD impaired at recognizing facial

ICD-10 expressions compared to $\mathrm{HC}\left(F_{46}=6.76\right.$ $P=0.02)$, particularly at low intensity or arousal

DSM-IV MDD impaired at recognizing facial expressions compared to $\mathrm{HC}(t=5.2$, $P<0.0001)$

DSM-IV MDD performed inferiorly to $\mathrm{HC}$ at emotional awareness of others $\left(F_{1,42}=5.5, P<0.05\right)$ Performance of the MDD group improved over the 7 weeks of treatment $\left(F_{1,42}=5.6\right.$, $P<0.05)$

DSM-IV MDD performed significantly worse on affective ToM task than $\mathrm{HC}\left(F_{1,91}=6.73\right.$, $P=0.01)$

BDI-II, MDD performed inferiorly to $\mathrm{HC}$ in facial HRSD affect recognition accuracy $\left(F_{1,38}=6.40\right.$, $P=0.02)$

DSM-IV Severe MDD less accurate than $\mathrm{HC}$ on affective ToM task $\left(t_{65}=2.24, P=0.03\right)$; no difference between mild/moderate MDD and $\mathrm{HC}$ or MDD groups

ICD-10 
Table 1 | Continued

\begin{tabular}{|c|c|}
\hline References & Aim \\
\hline $\begin{array}{l}\text { Surguladze } \\
\text { et al. (31) }\end{array}$ & $\begin{array}{l}\text { To investigate the accuracy and } \\
\text { response bias of depressed people to } \\
\text { affective facial expressions }\end{array}$ \\
\hline $\begin{array}{l}\text { Szily and } \\
\text { Kéri (32) }\end{array}$ & $\begin{array}{l}\text { To determine the impact of psychosis } \\
\text { risk in depression on social cognition }\end{array}$ \\
\hline $\begin{array}{l}\text { Wang } \\
\text { et al. (8) }\end{array}$ & $\begin{array}{l}\text { To determine if psychotic features in } \\
\text { depression impact social cognitive } \\
\text { performance }\end{array}$ \\
\hline
\end{tabular}

Method N $\quad N$ MA \pm SD; M:F] task

Social cognition

Mood

task

diagnosis

Clinical sample 24M:32F]

DSM-IV

MDD worse than $\mathrm{HC}$ in facial affect

recognition accuracy $\left(F_{1,42}=26.2, P<0.01\right)$

Case-control

$\operatorname{prMDD}=26, \mathrm{MDD}=42$,

RMET-R

DSM-IV

prMDD and MDD were less accurate than

Clinical sample

$\mathrm{HC}=50$ [21.2 $\pm 7.3 ; 44 \mathrm{M}: 73 \mathrm{~F}]$

Case-control

$\mathrm{pMDD}=23, \mathrm{npMDD}=33$,

RMET-R, FPT

ICD-10

$H C=53[26.8 \pm 4.4 ; 47 \mathrm{M}: 62 \mathrm{~F}]$

$\mathrm{HC}$ on $\operatorname{RMET}-\mathrm{R}\left(F_{2,230}=10.30, P<0.001\right)$

On RMET-R, pMDD inferior to both npMDD $(P=0.018)$ and $\mathrm{HC}(P=0.000)$, npMDD superior to $\mathrm{HC}(P=0.000)$

On FPT, HC superior to both $\mathrm{pMDD}$ $(U=0.000, P=0.000)$ and $\mathrm{npMDD}$ $(U=128.500, P=0.000), \mathrm{pMDD}$ inferior to $\operatorname{npMDD}(U=149.500, P=0.000)$

Case-control $\quad M D D=24, \mathrm{HC}=20[36.4 \pm 10.8 ; \quad$ RMET-R, MASC Outpatient sample 19M:25F]

et al. (2) cognitive performance between depressed patients and controls

Zobel To compare social cognitive

et al. (33) performance between depressed patients and controls $\begin{array}{lll}\text { Case-control } & \mathrm{MDD}=30, \mathrm{HC}=30[46.5 \pm 12.0 ; & \mathrm{BCPS} \\ \text { Clinical sample } & 27 \mathrm{M}: 33 \mathrm{~F}] & \text { WE. EL }\end{array}$

\section{(B) STUDIES INDICATING NON-SIGNIFICANT DIFFERENCES BETWEEN ACUTELY DEPRESSED INDIVIDUALS AND HEALTHY CONTROLS}

MDD $=12, \mathrm{HC}=15[36.6 \pm 12.8 . \mathrm{V}-\mathrm{SIR}, \mathrm{TOM}$ comic

et al. (7) in a clinical sample

Inpatient sample

$36 \mathrm{M}: 21 \mathrm{Fl}$

\begin{tabular}{|c|c|c|c|c|c|}
\hline $\begin{array}{l}\text { Bediou } \\
\text { et al. (34) }\end{array}$ & $\begin{array}{l}\text { To compare how depressed and } \\
\text { schizophrenic patients recognize facial } \\
\text { affect }\end{array}$ & $\begin{array}{l}\text { Case-control } \\
\text { Clinical sample }\end{array}$ & $\begin{array}{l}\mathrm{MDD}=20, \mathrm{HC}=20[32.9 \pm 9.8 ; \\
42 \mathrm{M}: 27 \mathrm{~F}]\end{array}$ & Self-created & DSM-IV \\
\hline $\begin{array}{l}\text { Bertoux } \\
\text { et al. (20) }\end{array}$ & $\begin{array}{l}\text { To evaluate a new social cognitive task } \\
\text { to distinguish depression from }\end{array}$ & $\begin{array}{l}\text { Case-control } \\
\text { Inpatient sample }\end{array}$ & $\begin{array}{l}\mathrm{MDD}=19, \mathrm{HC}=30[65.1 \pm 9.0 ; \\
47 \mathrm{M}: 39 \mathrm{~F}]\end{array}$ & Mini-SEA (PFA, sFPT) & DSM-IV \\
\hline
\end{tabular}

MDD inferior to $\mathrm{HC}$ in performance on MASC $\left(F_{1,42}=4.57, P<0.05\right)$, but equal on RMET-R $\left(F_{1,42}=0.74, P<0.40\right)$

DSM-IV MDD inferior to $\mathrm{HC}$ in BCPS sequence $(U=242.5, P=0.001)$, FOQ $(U=294.0$, $P=0.004)$, SOQ $(U=183.5, P=0.001)$; and WE.EL sequence $(U=282.0, P=0.012)$, FOQ $(U=297.0, P=0.016)$, SOQ $(U=234.0$, $\mathrm{P}=0.001)$

MDD performed non-significantly worse on V-SIR compared to HC. No group effect for ToM comic test

MDD and $\mathrm{HC}$ performed equally well on facial affect recognition

On total mini-SEA and component scores, MDD performed equally to $\mathrm{HC}$ 
Table 1 | Continued

\begin{tabular}{|c|c|c|c|c|c|c|}
\hline References & Aim & Method & $N[\mathrm{MA} \pm \mathrm{SD} ; \mathrm{M}: \mathrm{F}]$ & $\begin{array}{l}\text { Social cognition } \\
\text { task }\end{array}$ & $\begin{array}{l}\text { Mood } \\
\text { diagnosis }\end{array}$ & Results \\
\hline $\begin{array}{l}\text { Gollan } \\
\text { et al. (35) }\end{array}$ & $\begin{array}{l}\text { To identify differences in affective } \\
\text { information processing between } \\
\text { depressed patients and controls }\end{array}$ & $\begin{array}{l}\text { Case-control } \\
\text { Clinical sample }\end{array}$ & $\begin{array}{l}\mathrm{MDD}=37, \mathrm{HC}=29[35.1 \pm 9.3 \\
34 \mathrm{M}: 32 \mathrm{~F}]\end{array}$ & PFA & DSM-IV & $\begin{array}{l}\text { MDD and } \mathrm{HC} \text { performed equally in facial } \\
\text { affect recognition and intensity categorization }\end{array}$ \\
\hline $\begin{array}{l}\text { Gollan } \\
\text { et al. (36) }\end{array}$ & $\begin{array}{l}\text { To investigate how depressed patients } \\
\text { interpret facial affect of differing } \\
\text { intensity }\end{array}$ & $\begin{array}{l}\text { Case-control } \\
\text { Clinical sample }\end{array}$ & $\begin{array}{l}\mathrm{MDD}=44, \mathrm{HC}=44[29.5 \pm 9.8 \\
33 \mathrm{M}: 55 \mathrm{~F}]\end{array}$ & PFA & DSM-IV & $\begin{array}{l}\text { No significant main effect for group (MDD vs. } \\
\mathrm{HC} \text { ) on facial affect recognition accuracy }\end{array}$ \\
\hline $\begin{array}{l}\text { Joorman and } \\
\text { Gotlib (37) }\end{array}$ & $\begin{array}{l}\text { To examine depression-specific biases } \\
\text { in identification of affective facial } \\
\text { expressions }\end{array}$ & $\begin{array}{l}\text { Case-control } \\
\text { Outpatient sample }\end{array}$ & $\begin{array}{l}\mathrm{MDD}=23, \mathrm{SP}=27, \mathrm{HC}=26 \\
{[31.9 \pm 9.4 ; 21 \mathrm{M}: 51 \mathrm{~F}]}\end{array}$ & FEEST & DSM-IV & $\begin{array}{l}\mathrm{MDD}, \mathrm{SP} \text {, and } \mathrm{HC} \text { performed equally on facial } \\
\text { affect recognition }\end{array}$ \\
\hline $\begin{array}{l}\text { Matthews } \\
\text { et al. (38) }\end{array}$ & $\begin{array}{l}\text { To examine amygdala-cingulate } \\
\text { functional coupling in depression } \\
\text { during an emotional face matching task }\end{array}$ & $\begin{array}{l}\text { Case-control } \\
\text { Community sample }\end{array}$ & $\begin{array}{l}\mathrm{MDD}=15, \mathrm{HC}=16[24.4 \pm 5.3 \\
9 \mathrm{M}: 22 \mathrm{~F}]\end{array}$ & PFA & DSM-IV & $\begin{array}{l}\text { No difference between MDD and } \mathrm{HC} \text { for } \\
\text { accuracy or reaction time on face matching } \\
\text { task }\end{array}$ \\
\hline $\begin{array}{l}\text { Seidel } \\
\text { et al. (39) }\end{array}$ & $\begin{array}{l}\text { To measure automatic behaviors } \\
\text { toward affective facial expressions in } \\
\text { depression }\end{array}$ & $\begin{array}{l}\text { Case-control } \\
\text { Inpatient sample }\end{array}$ & $\begin{array}{l}\mathrm{MDD}=24, \mathrm{HC}=24[42.4 \\
24 \mathrm{M}: 24 \mathrm{~F}]\end{array}$ & VERT-K & DSM-IV & $\begin{array}{l}\text { MDD and } \mathrm{HC} \text { performed equally well on } \\
\text { facial affect recognition }\end{array}$ \\
\hline $\begin{array}{l}\text { Suslow } \\
\text { et al. (40) }\end{array}$ & $\begin{array}{l}\text { To examine spatial detection of facial } \\
\text { emotion in depressed inpatients } \\
\text { undergoing psychotherapy }\end{array}$ & $\begin{array}{l}\text { Prospective } \\
\text { longitudinal } \\
\text { case-control } \\
\text { Inpatient sample }\end{array}$ & $\begin{array}{l}\mathrm{MDD}=11, \mathrm{MDD} / \mathrm{AD}=11 \\
\mathrm{HC}=22[32.1 \pm 8.3 ; 14 \mathrm{M}: 30 \mathrm{~F}]\end{array}$ & FITCT & DSM-IV & $\begin{array}{l}\text { Both MDD groups performed equally to } \mathrm{HC} \\
\text { in spatial detection of facial affect, at two } \\
\text { time points } \\
\text { Performance did not significantly improve in } \\
\text { either group over the } 7 \text { weeks }\end{array}$ \\
\hline $\begin{array}{l}\text { Suslow } \\
\text { et al. (41) }\end{array}$ & $\begin{array}{l}\text { To assess awareness of masked facial } \\
\text { expressions and automatic amygdala } \\
\text { responses in depression }\end{array}$ & $\begin{array}{l}\text { Case-control } \\
\text { Inpatient sample }\end{array}$ & $\begin{array}{l}\mathrm{MDD}=30, \mathrm{HC}=26[37.5 \pm 12.4 \\
29 \mathrm{M}: 27 \mathrm{~F}]\end{array}$ & PFA & DSM-IV & $\begin{array}{l}\text { MDE and } \mathrm{HC} \text { did not differ in performance } \\
\text { when rating the valence of the masked facial } \\
\text { expressions }\end{array}$ \\
\hline $\begin{array}{l}\text { Wilbertz } \\
\text { et al. (22) }\end{array}$ & $\begin{array}{l}\text { To explore preoperational features of } \\
\text { ToM in depression }\end{array}$ & $\begin{array}{l}\text { Case-control } \\
\text { Clinical sample }\end{array}$ & $\begin{array}{l}\mathrm{MDD}=16, \mathrm{HC}=16[43.7 \pm 11.2 ; \\
16 \mathrm{M}: 16 \mathrm{~F}]\end{array}$ & MASC & DSM-IV & $\begin{array}{l}\text { MDD and } \mathrm{HC} \text { performed equally on MASC } \\
\text { multiple choice }\left(t_{30}=0.01, P=0.924\right) \text { and } \\
\text { open answers }\left(t_{30}=0.03, P=0.980\right)\end{array}$ \\
\hline
\end{tabular}

$A D$, anxiety disorder; BCPS, Brüne's cartoon picture story test; BDI-II, Beck depression inventory-II; DSM-IV, diagnostic and statistical manual of mental disorders-IV; FEEST, facial expressions of emotion: stimuli and tests; FEPT, facial emotion and perception test; FERT, facial expression recognition task; FITCT, face-in-the-crowd task; FOQ, first order question; FPT, faux pas task; GP, general practice; HC, healthy controls; HRSD, Hamilton rating scale for depression; ICD-10, international classification of diseases, 10th revision; LEAS, levels of emotional awareness Scale; MASC, movie for the assessment of social cognition; MA \pm SD, participants' mean age and standard deviation; MDD, major depressive disorder; MDE, major depressive episode; M:F, ratio of male to female participants; Mini-SEA, mini-social cognition and emotional assessment; $N$, number of participants; nPMDD, non-psychotic major depressive disorder; PFA, Ekman and Friesen's pictures of facial affect; $p M D D$, psychotic major depressive disorder; rMDD, remitted major depressive disorder; prMDD, major depressive disorder with psychosis risk; RMET-R, reading the mind in the eyes task, revised; sFPT, shortened faux pas task; SOQ, second-order question; SP, social phobia; ToM, theory of mind; WE.EL, Werden and Elikann test; VERT-K, Vienna emotion recognition tasks; VHI, virtual human interface; V-SIR, Versailles - situational intention reading. 
less likely than healthy controls to correctly identify positive emotions $(25,31)$, however, this is far from a consistent finding. In a case-control study of 130 inpatients, Csukly et al. (25) found a significant negative association between recognition of happy expressions and presence of a maladaptive schema, however no other associations of significance were found with any of the other studied expressions including sadness. A similar study involving 56 inpatients by Surguladze et al. (31) also demonstrated a link between severity of depression and difficulty recognizing happy expressions, but in contrast observed an even greater impairment in recognition of negative expressions.

Another important factor in social cognitive performance is the ability to detect subtle expressions of facial emotion. Several smaller case-control studies (44-66 participants) incorporated variations of intensity into the assessment of facial affect recognition. Patients with major depressive disorder were identified as more likely to misattribute the expression as being of a higher intensity (35). Furthermore, depressed patients were found to require a greater intensity of emotion than their non-depressed counterparts to identify happy expressions $(37,44)$ and less intensity to identify sad expressions $(36,37,42)$. Although the different research groups used a variety of different assessment tools, the degree of expression intensity may represent an important trend emerging within the body of literature.

Many studies incorporated assessment of reaction time, in addition to accuracy, for facial affect recognition. Several casecontrol studies showed individuals with major depressive disorder to have slower recognition of facial expressions than healthy controls $(30,31)$ and depressed patients with co-morbid anxiety to be slower in recognizing positive faces than both controls and non-anxious depressed (40). In a moderately sized case-control study, depressed patients were found to be significantly poorer at recognizing facial expressions when presented with an affective stimulus for 100 milliseconds, but equal to healthy controls when the time of stimulus was increased to 2,000 milliseconds (31). In contrast, reaction times were increased in some studies when depressed patients were confronted with sad (35) or neutral (30, 40) expressions. However, these represented a minority of results with the larger portion of investigators reporting no difference in reaction time $(23,28,38,41)$, throwing doubt over any potential association.

There were little data available investigating discrepancies in the way depressed and non-depressed subjects react to emotional stimuli. One group of researchers observed that depressed individuals demonstrate more avoidant behavior on an implicit joystick task when confronted by both negative and positive emotional stimuli, even when this information was correctly interpreted by the participant $(39,45)$. However, these studies both involved small numbers of participants ( 30 and 48 , respectively) and only looked at instinctive reaction to facial expression without investigation of functional implications.

\section{Affective theory of mind}

There was greater consistency in the literature regarding affective theory of mind in major depressive disorder. Almost all studies employed the Reading the Mind in the Eyes assessment task (46), which required participants to interpret the affective mental state portrayed in various cropped images of eyes. The clear majority of studies found that depressed patients were impaired in this skill compared to controls $(8,21,27,29,32)$. However, a separate study found depressed patients to be in fact more accurate than matched controls in identifying a negative emotional state, without any difference for neutral and positive states (2). This may indicate a bias toward negative emotions similar to the phenomenon observed with interpretation of facial expressions.

The only two studies that did not reveal a difference between groups on theory of mind performance indicated instead that the depressed group showed less perceptual reasoning than controls for the affective rather than cognitive components of theory of mind $(2,22)$. This preference against affective theory of mind was also demonstrated by Lee et al. (29) in a case-control study of 101 patients. Such findings may suggest that theory of mind deficits in major depressive disorder may be primarily on an emotional level.

A number of authors considered the effect of certain clinical features of depression on affective theory of mind performance, linking suicidal behaviors (47), excessive rumination (48), and anxiety (29) to impaired performance compared to patients who did not feature these symptoms. Additionally, patients with psychotic features of depression were significantly worse than depressed patients without these features $(8,21)$, which is in keeping with previous literature on psychotic disorders (1). However, risk of psychosis itself was not significant (32).

\section{Cognitive theory of mind}

A number of researchers also chose to use tools based on cognitive theory of mind ability in their assessment of possible social cognition impairments in depressed patients, with some evidence to suggest that patients with major depressive disorder have difficulties with these skills in comparison to healthy controls. In a case-control study involving 60 patients, Zobel et al. (33) found that depressed patients appear to be impaired on the key cognitive theory of mind tasks of interpreting both first- and second-order questions relating to social interactions. Further case-control studies by Cao et al. (21) and Wang et al. (8) also identified deficits amongst depressed patient populations in identifying social faux pas. However, as both these researchers chose to include psychotic depressed patients as a third subgroup as well as non-psychotic depressed patients and healthy controls, interpretation of these findings was difficult. Lastly, patients with major depressive disorder also showed poorer emotional awareness of what others were thinking compared to controls, but had good insight into their own emotional state (26). This was also manifest as a difficulty in showing empathy toward the feelings of others (22).

In contrast, there were also a number of studies that found little difference in cognitive theory of mind performance between the depressed and non-depressed. Wolkenstein et al. (2) found depressed patients to have difficulty integrating contextual information about other people or sequences of events, but was unable to identify any other significant theory of mind deficit. Three other small case-control studies found depressed and healthy participants to have similar outcomes in their assessments $(7,20,22)$.

\section{SOCIAL COGNITION IN ACUTE AND REMITTED DEPRESSIVE STATES}

Some authors also examined whether acutely depressed patients performed differently on social cognitive tasks compared to those 
with remitted major depressive disorder. A very small sample base was retrieved, with the three relevant studies being detailed in Table 2. Anderson et al. (23) found that patients in remission were more likely to identify anger compared to controls, while Bhagwagar et al. (43) obtained a similar result for fear only. This most likely indicates priming for negative emotions, consistent with the previously reported finding that depressed patients required less intensity to identify negative expressions $(23,36,42)$. LeMoult et al. (44) conducted a case-control study of 95 women, which indicated that patients with remitted major depressive disorder made fewer errors than controls on facial affect recognition overall, but required significantly greater emotional intensity to identify happy expressions than controls $(\mathrm{p}<0.01)$.

The relationship between acute and remitted major depressive disorder can also be considered in terms of treatment. A number of studies have considered the role of intervention, with one randomized controlled trial finding that acute administration of citalopram improved facial affect recognition accuracy of fear compared to placebo (43). Emotional awareness of others also improved following a course of inpatient psychoanalyticinteractional group therapy (26), indicating the potential utility of non-pharmacological approaches. This evidence suggests that the alterations in social cognitive ability that occur with depression are reversible if the depressive state is treated. This is supported by the observation of another study that impaired performance in the depressed group was confined to untreated patients and that depressed subjects taking anti-depressant medication performed equally to controls (23). Clinical improvement may also be a function of dosage, as one study observed that higher doses of anti-depressants produced a tendency to rate fewer expressions as $\operatorname{sad}(31)$.

Two longitudinal studies of serially assessed patients with no therapeutic intervention have found that response accuracy did not change over time $(40,42)$. Indeed, it was shown that labeling performance remains constant, even when symptom severity was seen to decrease significantly in the patient group over a 6 -month period (42). This stable impairment in facial affect recognition may indicate that depressed patients are vulnerable to social problems. Additionally, these investigations suggest that some of the variability seen in the results between groups may be due to depressed population samples being on pharmacotherapy whilst being tested. Longitudinal and interventional studies with a greater follow-up time would be useful however, as all these studies were quite short.

\section{EFFECT OF SEVERITY OF DEPRESSION ON SOCIAL COGNITIVE PERFORMANCE}

Social cognitive performance in major depressive disorder is linked to the severity of depressive symptoms, as described in Table 3. In particular, there is a significant negative association between social cognitive performance and a higher score on a validated depression severity scale $(26,29)$. A study that separated the depressed cohort into severe and mild/moderate groups found those in the severe category performed statistically poorer than controls, while the mild/moderate group were trend worse (29). Others have found an isolated association between increasing severity and a deficit

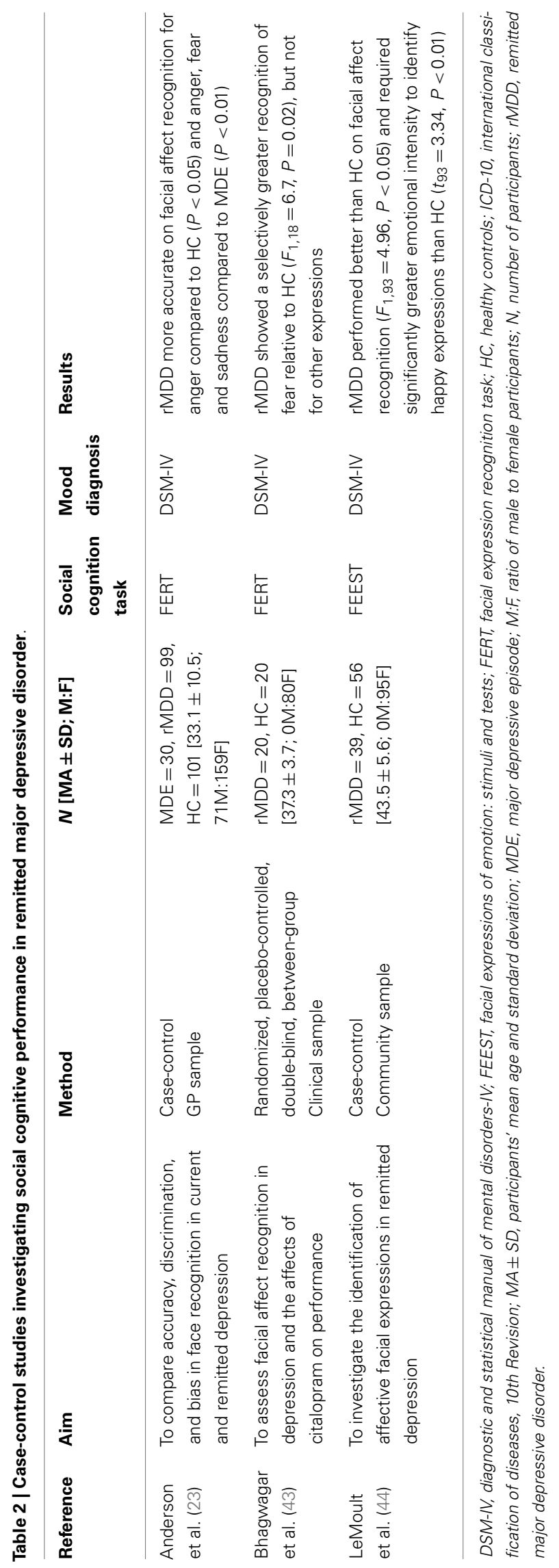




\begin{tabular}{|c|c|c|c|c|c|c|}
\hline Reference & Aim & Method & $N[\mathrm{MA} \pm \mathrm{SD} ; \mathrm{M}: \mathrm{F}]$ & $\begin{array}{l}\text { Social cognition } \\
\text { Task }\end{array}$ & $\begin{array}{l}\text { Diagnosis and } \\
\text { severity }\end{array}$ & Results \\
\hline Cao et al. (21) & $\begin{array}{l}\text { To investigate social cognitive } \\
\text { performance in esophageal } \\
\text { cancer patients with depression }\end{array}$ & $\begin{array}{l}\text { Case-control } \\
\text { Esophageal cancer } \\
\text { patient sample }\end{array}$ & $\begin{array}{l}\mathrm{pMDD}=32 \\
\mathrm{npMDD}=33, \mathrm{HC}=62 \\
{[33.1 \pm 10.5 ; 71 \mathrm{M}: 159 \mathrm{~F}]}\end{array}$ & RMET-R, FPT & BDI-II, BPRS & $\begin{array}{l}\text { In MDD, psychotic symptoms were negatively } \\
\text { correlated with performance on both RMET-R } \\
(r=-0.35, P<0.01) \text { and FPT }(r=-0.51 \\
P<0.01)\end{array}$ \\
\hline $\begin{array}{l}\text { Csukly } \\
\text { et al. (25) }\end{array}$ & $\begin{array}{l}\text { To identify associations between } \\
\text { depressive severity, maladaptive } \\
\text { schemas, and facial affect }\end{array}$ & $\begin{array}{l}\text { Case-control } \\
\text { Inpatient sample }\end{array}$ & $\begin{array}{l}\mathrm{MDD}=107, \mathrm{HC}=23 \\
{[41.1 \pm 11.3 ; 16 \mathrm{M}: 90 \mathrm{~F}]}\end{array}$ & $\mathrm{VHI}$ & DSM-IV, GSI, BDI & $\begin{array}{l}\text { One SD increase in GSI was associated with } \\
\text { decreased overall percentage recognition } \\
(B=-0.03) . \text { Happiness recognition was } \\
\text { negatively associated with both } \mathrm{BDI}\left(\chi^{2}=8.6 \text {, }\right. \\
P=0.004) \text { and SCL90-D }\left(\chi^{2}=7.9, P=0.03\right)\end{array}$ \\
\hline $\begin{array}{l}\text { Derntl } \\
\text { et al. (45) }\end{array}$ & $\begin{array}{l}\text { To investigate the neural } \\
\text { correlates of approach and } \\
\text { withdrawal to affective faces in } \\
\text { depressed patients }\end{array}$ & $\begin{array}{l}\text { Case-control } \\
\text { Inpatient sample }\end{array}$ & $\begin{array}{l}\mathrm{MDD}=15, \mathrm{HC}=30 \\
{[33.5 \pm 10.3 ; 12 \mathrm{M}: 18 \mathrm{~F}]}\end{array}$ & VERT-K & DSM-IV, BDI, HRSD & $\begin{array}{l}\text { MDD with higher HRSD scores showed less } \\
\text { approach to happy faces }(r=-0.602, P=0.017) \\
\text { and more avoidance to angry faces }(r=0.725, \\
P=0.002)\end{array}$ \\
\hline $\begin{array}{l}\text { Donges } \\
\text { et al. (26) }\end{array}$ & $\begin{array}{l}\text { To examine emotional awareness } \\
\text { in depressed inpatients following } \\
\text { a psychotherapy program }\end{array}$ & $\begin{array}{l}\text { Prospective longitudinal } \\
\text { case-control } \\
\text { Inpatient sample }\end{array}$ & $\begin{array}{l}\mathrm{MDD}=22, \mathrm{HC}=22 \\
{[32.1 \pm 8.6 ; 14 \mathrm{M}: 30 \mathrm{~F}]}\end{array}$ & LEAS & DSM-IV, BDI, ATO & $\begin{array}{l}\text { At baseline, degree of emotional awareness of } \\
\text { others correlated with BDI }(r=-0.29, P<0.05) \\
\text { and ATQ }(r=-0.27, P<0.05) \\
\text { At 7-week follow-up, there was no correlation } \\
\text { between performance and severity scores }\end{array}$ \\
\hline $\begin{array}{l}\text { Gollan } \\
\text { et al. (36) }\end{array}$ & $\begin{array}{l}\text { To investigate how depressed } \\
\text { patients interpret facial affect of } \\
\text { differing intensity }\end{array}$ & $\begin{array}{l}\text { Case-control } \\
\text { Clinical sample }\end{array}$ & $\begin{array}{l}\mathrm{MDD}=44, \mathrm{HC}=44 \\
{[29.5 \pm 9.8 ; 33 \mathrm{M}: 55 \mathrm{~F}]}\end{array}$ & PFA & DSM-IV, HRSD & $\begin{array}{l}\text { Depressive severity on HRSD was negatively } \\
\text { correlated with recognition accuracy for sad } \\
\text { faces ( } r_{44}=0.29, P=0.05 \text { ), but not other } \\
\text { emotions }\end{array}$ \\
\hline Lee et al. (29) & $\begin{array}{l}\text { To examine depressed patients' } \\
\text { abilities to identify mental states } \\
\text { from affective eye expressions }\end{array}$ & $\begin{array}{l}\text { Case-control } \\
\text { Outpatient sample }\end{array}$ & $\begin{array}{l}\mathrm{mMDD}=15 \\
\mathrm{sMDD}=37, \mathrm{HC}=30 \\
{[42.7 \pm 14.1 ; 0 \mathrm{M}: 82 \mathrm{~F}]}\end{array}$ & RMET-R & DSM-IV & $\begin{array}{l}\text { sMDD significantly less accurate than } \mathrm{HC} \text { on } \\
\text { affective ToM task }\left(t_{65}=2.24, P=0.03\right) \text {; while } \\
\text { mMDD were less accurate at a trend level } \\
\left(t_{43}=1.66, P=0.10\right)\end{array}$ \\
\hline $\begin{array}{l}\text { Leppänen } \\
\text { et al. (30) }\end{array}$ & $\begin{array}{l}\text { To determine if depression } \\
\text { biases the recognition of } \\
\text { emotionally neutral faces }\end{array}$ & $\begin{array}{l}\text { Case-control } \\
\text { Inpatient sample }\end{array}$ & $\begin{array}{l}\mathrm{MDD}=18, \mathrm{HC}=18 \\
{[44.9 \pm 9.9 ; 14 \mathrm{M}: 22 \mathrm{~F}]}\end{array}$ & PFA & ICD-10, BDI & $\begin{array}{l}\text { Increased BDI scores were correlated with the } \\
\text { proportion of incorrect ratings of neutral faces } \\
\text { as sad }\left(r_{36}=0.60, P<0.001\right)\end{array}$ \\
\hline $\begin{array}{l}\text { Milders } \\
\text { et al. (42) }\end{array}$ & $\begin{array}{l}\text { To investigate the stability of } \\
\text { emotion recognition } \\
\text { impairments over } 3 \text { months in } \\
\text { depressed patients }\end{array}$ & $\begin{array}{l}\text { Prospective longitudinal } \\
\text { case-control } \\
\text { Clinical sample }\end{array}$ & $\begin{array}{l}\mathrm{MDD}=19, \mathrm{HC}=25 \\
{[46.9 \pm 11.5 ; 15 \mathrm{M}: 29 \mathrm{~F}]}\end{array}$ & PFA & ICD-10, BDI-II, HRDS & $\begin{array}{l}\text { Sadness recognition was not associated with } \\
\text { symptom severity on HRSD or BDI-II, or } \\
\text { decreasing severity over time ( } P S<0.10)\end{array}$ \\
\hline
\end{tabular}




\section{Table 3 | Continued}

\begin{tabular}{|c|c|c|c|c|c|c|}
\hline Reference & Aim & Method & $N[\mathrm{MA} \pm \mathrm{SD} ; \mathrm{M}: \mathrm{F}]$ & $\begin{array}{l}\text { Social cognition } \\
\text { Task }\end{array}$ & $\begin{array}{l}\text { Diagnosis and } \\
\text { severity }\end{array}$ & Results \\
\hline \multirow[t]{2}{*}{$\begin{array}{l}\text { Raes } \\
\text { et al. (48) }\end{array}$} & $\begin{array}{l}\text { To determine if rumination is } \\
\text { associated with negative } \\
\text { interpretation of facial affect in } \\
\text { depression }\end{array}$ & $\begin{array}{l}\text { Cross-sectional } \\
\text { Clinical sample }\end{array}$ & $\begin{array}{l}\text { MDD =26 }[39.6 \pm 10.9 \\
9 M: 17 F]\end{array}$ & PFEQ & DSM-IV, BDI & $\begin{array}{l}\text { Rumination score correlated with perception of } \\
\text { negative facial affect }(r=0.51, P<0.001) \text {, but } \\
\text { not positive }\end{array}$ \\
\hline & & & & & & No correlation with BDI score for either \\
\hline $\begin{array}{l}\text { Surguladze } \\
\text { et al. (31) }\end{array}$ & $\begin{array}{l}\text { To investigate the accuracy and } \\
\text { response bias of depressed } \\
\text { people to affective facial } \\
\text { expressions }\end{array}$ & $\begin{array}{l}\text { Case-control } \\
\text { Clinical sample }\end{array}$ & $\begin{array}{l}\mathrm{MDD}=27, \mathrm{HC}=29 \\
{[45.0 \pm 11.6 ; 24 \mathrm{M}: 32 \mathrm{~F}]}\end{array}$ & FEEST & DSM-IV, HRSD, BDI & $\begin{array}{l}\text { HRSD correlated with identification of sadness } \\
\text { at } 100 \mathrm{~ms}(\rho=-0.44, P<0.05) \text { and } 2,000 \mathrm{~ms} \\
(\rho=-0.48, P<0.05) \text {, while BDI correlated with } \\
\text { happiness at } 100 \mathrm{~ms}(\rho=-0.49, P<0.05) \text { and } \\
\text { sadness at } 2,000 \mathrm{~ms}(\rho=-0.52, P<0.01)\end{array}$ \\
\hline $\begin{array}{l}\text { Szanto } \\
\text { et al. (47) }\end{array}$ & $\begin{array}{l}\text { To assess the relationship } \\
\text { between affective ToM, problem } \\
\text { solving, social functioning and } \\
\text { suicide in late-life depression }\end{array}$ & $\begin{array}{l}\text { Case-control } \\
\text { Clinical sample }\end{array}$ & $\begin{array}{l}\operatorname{sbMDD}=24 \\
\mathrm{nsbMDD}=38, \mathrm{HC}=28 \\
{[69.3 \pm 7.6 ; 39 \mathrm{M}: 51 \mathrm{~F}]}\end{array}$ & RMET-R & DSM-IV, HRSD, BSSI & $\begin{array}{l}\text { sbMDD impaired on affective ToM task } \\
\text { compared to } \mathrm{HC}\left(F_{2,87}=4.25, P=0.017\right) \text {, while } \\
\text { nsbMDD were no different to } \mathrm{HC}\end{array}$ \\
\hline $\begin{array}{l}\text { Wang } \\
\text { et al. (8) }\end{array}$ & $\begin{array}{l}\text { To determine if psychotic } \\
\text { features in depression affect } \\
\text { social cognitive performance }\end{array}$ & $\begin{array}{l}\text { Case-control } \\
\text { Inpatient sample }\end{array}$ & $\begin{array}{l}\mathrm{pMDD}=23 \\
\mathrm{npMDD}=33, \mathrm{HC}=53 \\
{[26.8 \pm 4.4 ; 47 \mathrm{M}: 62 \mathrm{~F}]}\end{array}$ & RMET-R, FPT & ICD-10 & $\begin{array}{l}\text { In MDD, psychotic symptoms were negatively } \\
\text { correlated with both RMET-R }(r=-0.357 \\
P=0.007) \text { and FPT }(r=-0.475, P<0.000)\end{array}$ \\
\hline $\begin{array}{l}\text { Wolkenstein } \\
\text { et al. (2) }\end{array}$ & $\begin{array}{l}\text { To investigate difference in social } \\
\text { cognitive performance between } \\
\text { depressed patients and controls }\end{array}$ & $\begin{array}{l}\text { Case-control } \\
\text { Outpatient sample }\end{array}$ & $\begin{array}{l}\mathrm{MDD}=24, \mathrm{HC}=20 \\
{[36.4 \pm 10.8 ; 19 \mathrm{M}: 25 \mathrm{~F}]}\end{array}$ & RMET-R, MASC & DSM-IV, QIDS & $\begin{array}{l}\text { QIDS correlated with selecting "no ToM' } \\
\text { responses on MASC }(r=-0.54, P<0.01) \text {, but } \\
\text { RMET-R was not associated with OIDS }\end{array}$ \\
\hline
\end{tabular}

ATQ, automatic thoughts questionnaire; BDI, Beck depression inventory; BDI-II, Beck depression inventory-II; BPRS, brief psychiatric rating scale; BSSI, Beck scale for suicidal ideation; DSM-IV, diagnostic and statistical manual of mental disorders-IV; GSI, global severity index; FEEST, facial expressions of emotion: stimuli and tests; FPT, faux pas task; HC, healthy controls; HRSD, Hamilton rating scale for depression; ICD-10, international classification of diseases, 10th revision: LEAS, levels of emotional awareness scale; $M A \pm S D$, participants' mean age and standard deviation; $M D D$, major depressive disorder: M:F, ratio of male to female participants; MASC, movie for the assessment of social cognition; mMDD, mild/moderate major depressive disorder; N, number of participants; npMDD, non-psychotic major depressive disorder; nsbMDD, major depressive disorder with no suicidal behavior; PFA, Ekman and Friesen's pictures of facial affect; PFEQ, perception of facial expressions questionnaire; pMDD, psychotic major depressive disorder; OIDS, quick inventory of depressive symptoms; RMET-R, reading the mind in the eyes task, revised; SBMDD, major depressive disorder with suicidal behavior; SCL90-D, symptom checklist 90 depression subscale; $S D$, standard deviation; SMDD, severe major depressive disorder; ToM, theory of mind; VERT-K, Vienna emotion recognition tasks; VHI, virtual human interface. 
responding to happiness $(25,31)$ or an advantage for recognizing sadness $(30,36)$.

These findings remain consistent with previous evidence suggesting a negative interpretative bias in emotional recognition. Theory of mind ability is also affected, as one study showed that increasing depressive severity was associated with responses that showed poor understanding of mental states (2).

In addition to severity of symptoms overall, the presence of certain severe symptoms also has an impact. Suicidal behavior and psychotic features are features that indicate a severe depressive illness and, as reported previously, both strongly correlate with the impaired interpretation of social stimuli $(8,21,47)$. Therefore, the phenotype of the illness is important in addition to the burden of symptoms.

The link observed between social cognitive performance and severity of major depressive disorder could also help explain the discrepancies observed in the group difference results, as studies that have a high proportion of milder depression cases may not achieve significant results. Nevertheless, there were also some studies that found no association with symptom severity (42), while another showed a negative association between severity and sadness accuracy (31).

\section{DISCUSSION}

This review of the literature demonstrates a number of emerging trends in the way that individuals with major depressive disorder process and interpret socially salient information. Importantly, a negative bias may exist in the way that depressed subjects recognize emotion, which manifests as performance differences according to valence of emotion. Additionally, the review indicates that social cognitive performance may be related to severity of the depressive illness, with more pronounced deficits being associated with increased scores on depressive symptom scales. Some authors have suggested that depressed subjects may require greater intensity of emotion and a longer reaction time when interpreting emotional stimuli compared to controls.

The literature, however, remains equivocal regarding many aspects of the relationship of social cognition and major depressive disorder, with a paucity of evidence in the domains of prosody and body language as well as limited data investigating patients in clinical remission. A noteworthy number of studies do not support these trends with some even finding no observed group differences between the depressed and controls in overall performance on tests of social cognitive function. This would suggest that any deficits in depression are subtler than in other disorders and may not be identified by broad measures of functioning.

One explanation for this variation in findings could be the predisposition of depressed patients to negatively interpret social stimuli. This bias would appear to improve performance for negatively valenced stimuli whilst simultaneously impairing performance for positively or neutrally valenced stimuli. The net effect of this bias could reduce statistical significance for overall performance on a task. Thus, the true differences in facial affect recognition may be masked if valence is not taken into account.

This observed negative interpretive bias on social cognitive tasks is mood-congruent and consistent with the cognitive paradigm of depression, as proposed by Beck $(49,50)$. This conceptualization of depression proposes that the thoughts, interpretations, and attitudes of an individual play an important role in the pathogenesis of the disorder. As major depressive disorder severely affects emotional states, it would fit that the deficits in social cognition would predominantly occur in the emotional domain, rather than in the cognitive skills of interpreting beliefs and intentions. The trends emergent in this review would support this, as the evidence is far more conclusive from tests assessing the emotional domain of social cognition, through both facial affect recognition and affective theory of mind. However some uncertainty remains, as there is little data available in cognitive theory of mind on which to base this assertion.

Few authors have addressed the important conceptual aspect of general cognition. Several cognitive domains, such as attention, memory, and executive functioning, have previously been found to be impaired in major depressive disorder $(51,52)$, implying that cognitive deficits may play a role in the pathophysiology of not only depression but also the associated impairments in general functioning or quality of life. General cognitive skills are crucial for the performance in tasks of social cognition tasks and their role is an important, unquantified factor in the studies covered by this review.

Indeed, difficulties with social interaction observed in patients with major depressive disorder may, at least in part, be due to an impaired ability to interpret emotional stimuli and mental states. In fact, social cognitive performance in depression may impact on the development of the disorder through impairing social functioning. Inaccurate assessments of feedback from interpersonal interactions exacerbate maladaptive thought processes, ultimately affecting mood. This could then diminish motivation to engage in social interaction, which would reduce reward from socializing and further intensify isolation. Awareness of social cognitive ability could be a beneficial component in cognitive-based psychotherapies.

\section{METHODOLOGICAL LIMITATIONS}

The discrepancies in results between some studies may be due to the variety of different tools employed to measure social cognition. Multiple measures exist for each component of social cognition and the tools are often tailored to the specific hypotheses of the investigation. This prevents accurate comparison between results, as well as limiting the reproducibility. Additionally, the majority of studies on social cognition use a unimodal design that exclusively focuses on one domain of social cognition, most commonly emotion recognition. There would be benefit in employing a study design that tests multiple domains in the same population. Some components of social cognition, such as prosody or body language, would also benefit from further directed research in major depressive disorder. It is difficult to make confident conclusions from only a small collection of studies.

Even the term "social cognition" is not universally used throughout the literature, with some authors preferring "social perception" $(1,4)$. This also creates a challenge when searching the literature, as different databases categorize the literature under different headings - Medline uses "social perception," Embase uses "social cognition," and PsychINFO uses both. The search is further complicated by the large number of individual social cognitive 
domains, meaning that some relevant articles may have been overlooked if not linked under the headings of social cognition or social perception. This is evident through the relatively large number of additional studies indentified for this review through the reference lists of included papers. A more targeted search with specific keywords identifying "prosody" and "theory of mind" may have also yielded greater results.

\section{FUTURE DIRECTIONS}

A clear need exists for further research, particularly in domains such as prosody and body language interpretation, which have not yet been well-described in a major depressive disorder population. In general, larger longitudinal studies of major depressive disorder would be helpful in furthering understanding of the relationship between acute and remitted depression, as well as response to treatment. Agreement on or standardization of both terminology and testing in the area of social cognition would be a helpful advent and allow for greater reproducibility and ease for comparison of results.

Understanding the relationship between major depressive disorder and social cognitive performance is important in characterizing both the etiology and phenotypology of major depressive disorder. In terms of potential implications for therapy, the results of two of the interventional studies included in this review indicated that treatment with anti-depressants, in particular citalopram, had a normalizing effect for a number of the observed social cognition defects of facial affect recognition. These findings suggest that the changes to social cognitive skills in depression are reversible. Despite being amenable to pharmacotherapy, it has not yet been established whether the observed findings impact on daily functioning and quality of life independent of that from depression. It is therefore important to quantify the functional burden, if any, of impaired social cognitive performance in major depressive disorder to determine its specific clinical relevance. Further research in this area would also be pertinent.

\section{CONCLUSION}

Patients with major depressive disorder appear to interpret emotional stimuli differently to healthy controls, although this is not a consistent finding throughout the recent literature. The difficulties with social interaction and functioning observed in depressed patients may, at least in part, be due to an altered ability to correctly interpret emotions or mental states. It appears that depressed patients may struggle more with subtle or nuanced expressions of emotion, as well as demonstrating a mood-congruent bias for interpreting stimuli more negatively. These features are linked with severity of the illness and may persist even in the remitted state. However, it appears that some impairments are at least partially reversible using anti-depressants or psychotherapy. Further research is required in this area to better understand the functional impact of these findings and the role of targeted therapy in improving how depressed individuals interact socially.

\section{ACKNOWLEDGMENTS}

The authors would like to thank Maureen Bell from The Barr Smith Library for her insight and assistance in refining the literature search terms and Alison Fraser for her efforts in proofreading the manuscript. Financial support for this study was received from the Royal Adelaide Hospital Honors Scholarship and the St John Ambulance South Australia Education Support Grant.

\section{REFERENCES}

1. Kandalaft MR, Didehbani N, Cullum CM, Krawczyk DC, Allen TT, Tamminga CA, et al. The Wechsler ACS social perception subtest: a preliminary comparison with other measures of social cognition. J Psychoeduc Assess (2012) 30:455-65. doi:10.1177/0734282912436411

2. Wolkenstein L, Schonenberg M, Schirm E, Hautzinger M. I can see what you feel, but I can't deal with it: impaired theory of mind in depression. J Affect Disord (2011) 132(1-2):104-11. doi:10.1016/j.jad.2011.02.010

3. Shamay-Tsoory SG, Aharon-Peretz J, Perry D. Two systems for empathy: a double dissociation between emotional and cognitive empathy in inferior frontal gyrus versus ventromedial prefrontal lesions. Brain (2009) 132(3):617-27. doi:10.1093/brain/awn279

4. Holdnack J, Goldstein G, Drozdick L. Social perception and WAIS-IV performance in adolescents and adults diagnosed with Asperger's syndrome and autism. Assessment (2011) 18(2):192-200. doi:10.1177/1073191110394771

5. American Psychiatric Association. Diagnostic and Statistical Manual of Mental Disorders (4th ed., text rev.). Washington, DC: American Psychiatric Association (2000).

6. Tse WS, Bond AJ. The impact of depression on social skills: a review. J Nerv Ment Dis (2004) 192(4):260-8. doi:10.1097/01.nmd.0000120884.60002.2b

7. Bazin N, Brunet-Gouet E, Bourdet C, Kayser N, Falissard B, Hardy-Bayle $\mathrm{MC}$, et al. Quantitative assessment of attribution of intentions to others in schizophrenia using an ecological video-based task: a comparison with manic and depressed patients. Psychiatry Res (2009) 167(1-2):28-35. doi:10.1016/j. psychres.2007.12.010

8. Wang YG, Wang YQ, Chen SL, Zhu CY, Wang K. Theory of mind disability in major depression with or without psychotic symptoms: a componential view. Psychiatry Res (2008) 161(2):153-61. doi:10.1016/j.psychres.2007.07.018

9. Weniger G, Lange C, Ruther E, Irle E. Differential impairments of facial affect recognition in schizophrenia subtypes and major depression. Psychiatry Res (2004) 128(2):135-46. doi:10.1016/j.psychres.2003.12.027

10. Demenescu LR, Kortekaas R, den Boer JA, Aleman A. Impaired attribution of emotion to facial expressions in anxiety and major depression. PLoS One (2010) 5(12):e15058. doi:10.1371/journal.pone.0015058

11. Bourke C, Douglas K, Porter R. Processing of facial emotion expression in major depression: a review. Aust N Z J Psychiatry (2010) 44(8):681-96. doi:10.3109/00048674.2010.496359

12. Harmer CJ, Goodwin GM, Cowen PJ. Why do antidepressants take so long to work? A cognitive neuropsychological model of antidepressant drug action. $\mathrm{Br}$ J Psychiatry (2009) 195(2):102-8. doi:10.1192/bjp.bp.108.051193

13. Venn HR, Watson S, Gallagher P, Young AH. Facial expression perception: an objective outcome measure for treatment studies in mood disorders? Int J Neuropsychopharmacol (2006) 9(2):229-45. doi:10.1017/S1461145705006012

14. Bos EH, Bouhuys AL, Geerts E, Van Os TW, Van der Spoel ID, Brouwer WH, et al. Cognitive, physiological, and personality correlates of recurrence of depression. J Affect Disord (2005) 87(2-3):221-9. doi:10.1016/j.jad.2005.04.001

15. Kan Y, Mimura M, Kamijima K, Kawamura M. Recognition of emotion from moving facial and prosodic stimuli in depressed patients. J Neurol Neurosurg Psychiatry (2004) 75(12):1667-71. doi:10.1136/jnnp.2004.036079

16. Elliott R, Zahn R, Deakin JW, Anderson IM. Affective cognition and its disruption in mood disorders. Neuropsychopharmacol (2011) 36(1):153-82. doi:10.1038/npp.2010.77

17. Leppänen JM. Emotional information processing in mood disorders: a review of behavioral and neuroimaging findings. Curr Opin Psychiatry (2006) 19(1):34-9. doi:10.1097/01.yco.0000191500.46411.00

18. Phillips ML, Drevets WC, Rauch SL, Lane R. Neurobiology of emotion perception II: implications for major psychiatric disorders. Biol Psychiatry (2003) 54(5):515-28. doi:10.1016/S0006-3223(03)00171-9

19. Stuhrmann A, Suslow T, Dannlowski U. Facial emotion processing in major depression: a systematic review of neuroimaging findings. Biol Mood Anxiety Disord (2011) 1:10. doi:10.1186/2045-5380-1-10

20. Bertoux M, Delavest M, de Souza LC, Funkiewiez A, Lepine JP, Fossati P, et al. Social cognition and emotional assessment differentiates frontotemporal 
dementia from depression. J Neurol Neurosurg Psychiatry (2012) 83(4):411-6. doi:10.1136/jnnp-2011-301849

21. Cao Y, Zhao Q-D, Hu L-J, Sun Z-Q, Sun S-P, Yun W-W, et al. Theory of mind deficits in patients with esophageal cancer combined with depression. World J Gastroenterol (2013) 19(19):2969-73. doi:10.3748/wjg.v19.i19.2969

22. Wilbertz G, Brakemeier EL, Zobel I, Harter M, Schramm E. Exploring preoperational features in chronic depression. J Affect Disord (2010) 124(3):262-9. doi:10.1016/j.jad.2009.11.021

23. Anderson IM, Shippen C, Juhasz G, Chase D, Thomas E, Downey D, et al. Statedependent alteration in face emotion recognition in depression. Br J Psychiatry (2011) 198(4):302-8. doi:10.1192/bjp.bp.110.078139

24. Csukly G, Czobor P, Szily E, Takács B, Simon L. Facial expression recognition in depressed subjects: the impact of intensity level and arousal dimension. J Nerv Ment Dis (2009) 197(2):98-103. doi:10.1097/NMD.0b013e3181923f82

25. Csukly G, Telek R, Filipovits D, Takacs B, Unoka Z, Simon L. What is the relationship between the recognition of emotions and core beliefs: associations between the recognition of emotions in facial expressions and the maladaptive schemas in depressed patients. J Behav Ther Exp Psychiatry (2011) 42(1):129-37. doi:10.1016/j.jbtep.2010.08.003

26. Donges U-S, Kersting A, Dannlowski U, Lalee-Mentzel J, Arolt V, Suslow T. Reduced awareness of others' emotions in unipolar depressed patients. J Nerv Ment Dis (2005) 193(5):331-7. doi:10.1097/01.nmd.0000161683.02482.19

27. Harkness KL, Washburn D, Theriault JE, Lee L, Sabbagh MA. Maternal history of depression is associated with enhanced theory of mind in depressed and nondepressed adult women. Psychiatry Res (2011) 189(1):91-6. doi:10.1016/j. psychres.2011.06.007

28. Langenecker SA, Bieliauskas LA, Rapport LJ, Zubieta J-K, Wilde EA, Berent S. Face emotion perception and executive functioning deficits in depression. J Clin Exp Neuropsychol (2005) 27(3):320-33. doi:10.1080/13803390490490515720

29. Lee L, Harkness KL, Sabbagh MA, Jacobson JA. Mental state decoding abilities in clinical depression. J Affect Disord (2005) 86(2-3):247-58. doi:10.1016/j.jad. 2005.02.007

30. Leppänen JM, Milders M, Bell JS, Terriere E, Hietanen JK. Depression biases the recognition of emotionally neutral faces. Psychiatry Res (2004) 128(2):123-33. doi:10.1016/j.psychres.2004.05.020

31. Surguladze SA, Young AW, Senior C, Brebion G, Travis MJ, Phillips ML Recognition accuracy and response bias to happy and sad facial expressions in patients with major depression. Neuropsychol (2004) 18(2):212-8. doi:10.1037/0894-4105.18.2.212

32. Szily E, Keri S. Anomalous subjective experience and psychosis risk in young depressed patients. Psychopathol (2009) 42(4):229-35. doi:10.1159/000218520

33. Zobel I, Werden D, Linster H, Dykierek P, Drieling T, Berger M, et al. Theory of mind deficits in chronically depressed patients. Depress Anxiety (2010) 27(9):821-8. doi:10.1002/da.20713

34. Bediou B, Krolak-Salmon P, Saoud M, Henaff MA, Burt M, Dalery J. et al. Facial expression and sex recognition in schizophrenia and depression. Can J Psychiatry (2005) 50(9):525-33.

35. Gollan JK, Pane HT, McCloskey MS, Coccaro EF. Identifying differences in biased affective information processing in major depression. Psychiatry Res (2008) 159(1):18-24. doi:10.1016/j.psychres.2007.06.011

36. Gollan JK, McCloskey M, Hoxha D, Coccaro EF. How do depressed and healthy adults interpret nuanced facial expressions? J Abnorm Psychol (2010) 119(4):804-10. doi:10.1037/a0020234

37. Joormann J, Gotlib IH. Is this happiness I see? Biases in the identification of emotional facial expressions in depression and social phobia. J Abnorm Psychol (2006) 115(4):705-14. doi:10.1037/0021-843X.115.4.705

38. Matthews SC, Strigo IA, Simmons AN, Yang TT, Paulus MP. Decreased functional coupling of the amygdala and supragenual cingulate is related to increased depression in unmedicated individuals with current major depressive disorder. J Affect Disord (2008) 111(1):13-20. doi:10.1016/j.jad.2008.05.022

39. Seidel EM, Habel U, Finkelmeyer A, Schneider F, Gur RC, Derntl B. Implicit and explicit behavioral tendencies in male and female depression. Psychiatry Res (2010) 177(1-2):124-30. doi:10.1016/j.psychres.2010.02.001
40. Suslow T, Dannlowski U, Lalee-Mentzel J, Donges U-S, Arolt V, Kersting A. Spatial processing of facial emotion in patients with unipolar depression: a longitudinal study. J Affect Disord (2004) 83(1):59-63. doi:10.1016/j.jad.2004. 03.003

41. Suslow T, Konrad C, Kugel H, Rumstadt D, Zwitserlood P, Schöning S, et al. Automatic mood-congruent amygdala responses to masked facial expressions in major depression. Biol Psychiatry (2010) 67(2):155-60. doi:10.1016/j.biopsych. 2009.07.023

42. Milders M, Bell S, Platt J, Serrano R, Runcie O. Stable expression recognition abnormalities in unipolar depression. Psychiatry Res (2010) 179(1):38-42. doi:10.1016/j.psychres.2009.05.015

43. Bhagwagar Z, Cowen PJ, Goodwin GM, Harmer CJ. Normalization of enhanced fear recognition by acute SSRI treatment in subjects with a previous history of depression. Am J Psychiatry (2004) 161(1):166-8. doi:10.1176/ appi.ajp.161.1.166

44. LeMoult J, Joormann J, Sherdell L, Wright Y, Gotlib IH. Identification of emotional facial expressions following recovery from depression. J Abnorm Psychol (2009) 118(4):828-33. doi:10.1037/a0016944

45. Derntl B, Seidel EM, Eickhoff SB, Kellermann T, Gur RC, Schneider F, et al. Neural correlates of social approach and withdrawal in patients with major depression. Soc Neurosci (2011) 6(5-6):482-501. doi:10.1080/17470919.2011. 579800

46. Baron-Cohen S, Wheelwright S, Hill J, Raste Y, Plumb I. The "Reading the Mind in the Eyes" test revised version: a study with normal adults, and adults with Asperger syndrome or high-functioning autism. J Child Psychol Psychiatry (2001) 42(2):241-51. doi:10.1111/1469-7610.00715

47. Szanto K, Dombrovski AY, Sahakian BJ, Mulsant BH, Houck PR, Reynolds CF III, et al. Social emotion recognition, social functioning, and attempted suicide in late-life depression. Am J Geriatr Psychiatry (2012) 20(3):257-65. doi:10.1097/JGP.0b013e31820eea0c

48. Raes F, Hermans D, Williams JM. Negative bias in the perception of others' facial emotional expressions in major depression: the role of depressive rumination. J Nerv Ment Dis (2006) 194(10):796-9. doi:10.1097/01.nmd.0000240187. 80270.bb

49. Beck AT. Thinking and depression: I. idiosyncratic content and cognitive distortions. Arch Gen Psychiatry (1963) 9(4):324-33. doi:10.1001/archpsyc.1963. 01720160014002

50. Beck AT. Thinking and depression: II. theory and therapy. Arch Gen Psychiatry (1964) 10(6):561-71. doi:10.1001/archpsyc.1964.01720240015003

51. Baune BT, Miller R, McAfoose J, Johnson M, Quirk F, Mitchell D. The role of cognitive impairment in general functioning in major depression. Psychiatry Res (2010) 176(2-3):183-9. doi:10.1016/j.psychres.2008.12.001

52. McDermott LM, Ebmeier KP. A meta-analysis of depression severity and cognitive function. JAffect Disord (2009) 119(1-3):1-8. doi:10.1016/j.jad.2009.04.022

Conflict of Interest Statement: The authors declare that the research was conducted in the absence of any commercial or financial relationships that could be construed as a potential conflict of interest.

Received: 06 July 2014; accepted: 25 November 2014; published online: 11 December 2014.

Citation: Weightman MJ, Air TM and Baune BT (2014) A review of the role of social cognition in major depressive disorder. Front. Psychiatry 5:179. doi: 10.3389/fpsyt.2014.00179

This article was submitted to Affective Disorders and Psychosomatic Research, a section of the journal Frontiers in Psychiatry.

Copyright $\odot 2014$ Weightman, Air and Baune. This is an open-access article distributed under the terms of the Creative Commons Attribution License (CC BY). The use, distribution or reproduction in other forums is permitted, provided the original author(s) or licensor are credited and that the original publication in this journal is cited, in accordance with accepted academic practice. No use, distribution or reproduction is permitted which does not comply with these terms. 